\title{
Characterization of the thermal flux transferred by the plasma arc to the surface of the liquid bath in the Plasma Arc Melting Cold Hearth Refining process (PAMCHR)
}

Léa Décultot ${ }^{1,2}$, Alain Jardy ${ }^{1}$, Stéphane Hans ${ }^{2}$, Emiliane Doridot ${ }^{2}$, Jérôme Delfosse ${ }^{3}$, Fabienne Ruby-Meyer ${ }^{4}$, JeanPierre Bellot ${ }^{1}$.

1. Institut Jean Lamour - UMR CNRS 7198, LabEx DAMAS, Université de Lorraine, 2 allée André Guinier, Campus Artem, 54000, Nancy, France.

2. Aubert \& Duval Les Ancizes - 63770, Les Ancizes Cedex BP1, France.

3. Safran Tech - Rue des Jeunes Bois, Châteaufort, 78772, Magny-les-Hameaux, France.

4. MetaFensch - 109 rue de Thionville, 57270, Uckange, France.

\section{Abstract}

Europe is a major provider of titanium scrap but until now there has been no european facility dedicated to the production of aeronautical quality titanium alloys by recycling. UKAD, a joint-venture between Aubert \& Duval and UKTMP, ADEME and Crédit Agricole Center France, created the company EcoTitanium, where the recycling of machining scraps is achieved using the Plasma Arc Melting Cold Hearth Refining (PAMCHR) process with the aim of producing such alloy ingots.

The determination of the heat flux transferred from the plasma column to the surface of the liquid bath is an important issue needed for the development of a future 3D process modeling based on Ansys-Fluent CFD software. With this preliminary aim of predicting the heat flux, a study coupling pilot furnace testing and numerical modeling has been performed. Melting tests were carried out in a pilot PAMCHR furnace in MetaFensch, with a stationary torch. In parallel, the different contributions of the heat flux transferred to the surface of the liquid bath were identified and implemented in a simple 2D axisymmetric heat transfer model. Numerical results are compared to the experimental measurements, in order to define the heat flux transferred from the plasma torch.

\section{Introduction}

Hearth Refining (HR) followed by single VAR (Vacuum Arc Remelting) has been set-up as an alternative route to produced certified premium grade titanium alloys, as compared to the conventional route involving three successive VAR melts. Indeed, HR processes include a refining stage in a horizontal water-cooled crucible designed to easily eliminate Low Density Inclusions (TiN, TiO...) due to the long metal residence time that allow the dissolution of solid particles. Moreover, these processes remove readily the High Density Inclusions (WC particles...) by exploiting the density separation: the inclusions settle to the bottom of the refining crucible and are trapped in the mushy zone.

HR basically stands for two different processes: Electron Beam Cold Hearth Refining (EBCHR) and Plasma Arc Melting Cold Hearth Refining (PAMCHR). The power used in the EBCHR process is generated by electron guns, which sweep rapidly the liquid surface to provide a quasi-stationary heat supply. These electron guns require a high vacuum, which favors the volatilization losses of alloy constituents with a high vapor pressure such as Al and Cr. Minimizing the volatilization is the main advantage of the PAMCHR process, which uses plasma torches as the heat source: the process is conducted under an atmosphere of inert gas, with an operating pressure lying between 0.4 bar and 1 bar. As compared to the EBCHR process, the determination of the heat distribution transfer to the bath is more complex in the PAMCHR case.

In 1997, Huang et al. [1] developed a model of the PAMCHR refining stage, assuming a Gaussian distribution of the heat transfer from the plasma arc applied to the bath surface. In $1999 \mathrm{Li}$ et al. [2] developed a torch model for a reversed polarity plasma torch, and calculated a non-Gaussian distribution of the heat transfer: the predicted heat flux reached a 
maximum value $20 \mathrm{~mm}$ away from the torch center. Different studies [3-5] have discussed the plasma heat flux as the composition of three main distributions: a convective-diffusive contribution, an electric contribution and a radiative contribution. Nevertheless, more recently, a team from UBC [6,7] neglected the electric contribution and determined, based on experimental trials, that the heat transfer from the plasma plume could be approximated by the sum of two Gaussian inputs: one for the convective part and the second for the radiative contribution.

The present work focusses on the determination of the heat flux distribution transferred from the plasma plume to the metal bath under real conditions of the PAMCHR process. Experimental tests have been achieved in a pilot furnace, and a numerical model has been developed to simulate the trials: a comparison is carried out between experimental results and numerical ones in order to quantify the overall distribution. In addition, these trials and numerical model have been used to analyze the impact of Lorentz forces on the liquid flow.

\section{Material and experiments}

\section{Experimental method}

A set of trials using thermocouple measurements has been achieved in a pilot furnace in Metafensch, a public research and development center. The trials mainly consisted in recording the temperature evolution during and after the melting of a Ti64 cylindrical part with a stationary plasma torch.

The dimensions of the Ti64 block are given in Figure 1a. The plasma torch power was set at $177 \mathrm{~kW}$, and helium was used for the torch operation under a chamber pressure of 400 mbar. The metal part was instrumented with 11 K-type thermocouples at the depth of $40 \mathrm{~mm}$ (red line in Figure 1a). This depth was chosen to avoid any contact between the thermocouples and molten Ti64, which would destroy the thermocouples. The latter, numbered TC1 to TC11, were positioned along two perpendicular lines in order to assess the symmetry of temperature distribution: this layout is shown on Figure 1b.

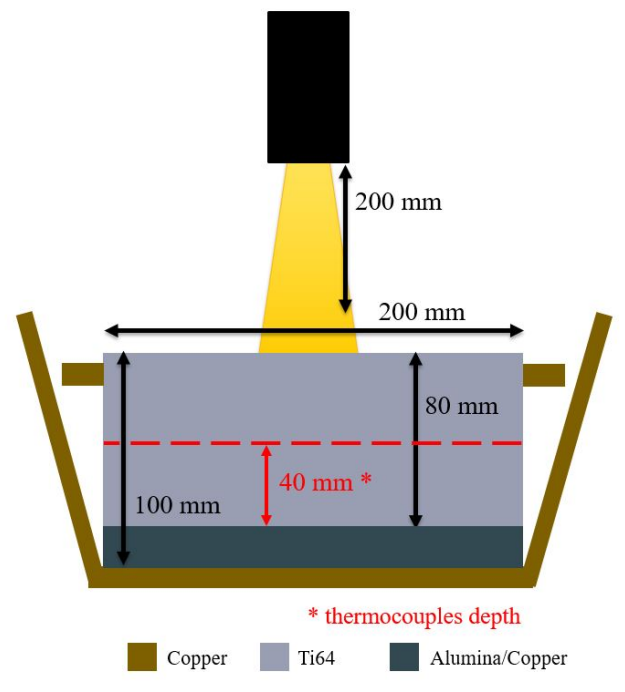

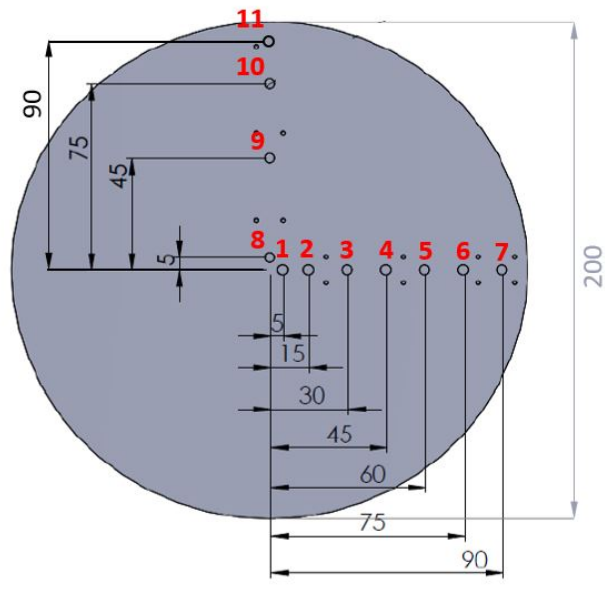




\section{Figure 1a. Schematic representation of the trial experiment}

Figure 1b. Schematic representation of thermocouple layout in the Ti64 block

Two trials have been carried out, differing through the Ti64/copper contact (Figure 2). In this way, electric current lines should lead to different self-induced magnetic fields, hence different Lorentz forces.

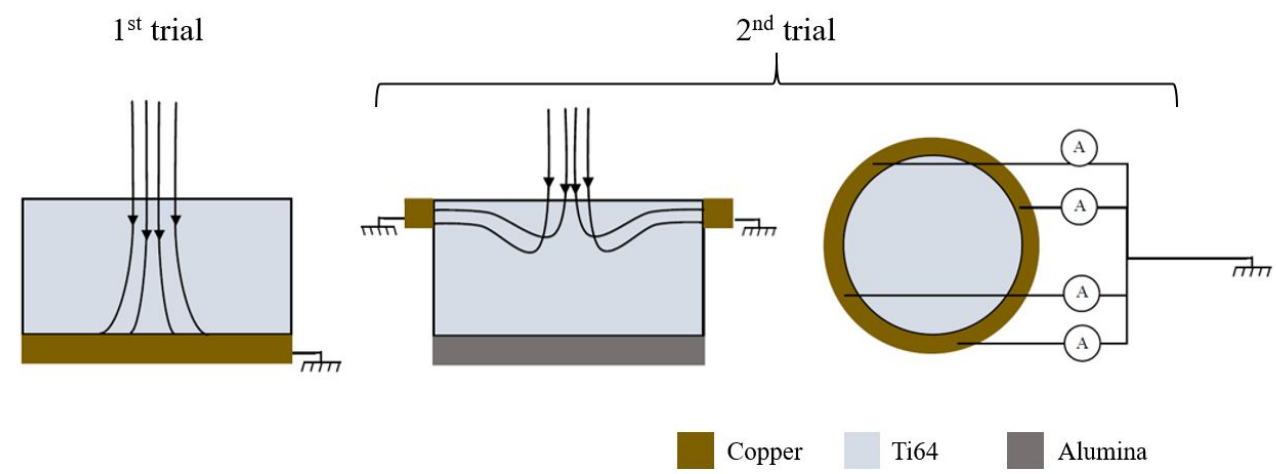

Figure 2. Schematic representation of the two trials

\section{Experimental results}

The total heating time was $50 \mathrm{~s}$ for the first trial and $54 \mathrm{~s}$ for the second one. In each case, the final shape of the liquid bath was characterized (Figures 3 and 4) and the evolution of the temperature measured by all thermocouples was recorded (Figure 5). A slightly larger liquid bath radius is noticed for the second trial (see Figure 3). This increase can be caused by the longer time of heating by the plasma torch. This additional time seems to impact more the bath radius than its depth which is quite similar in both cases (see Figure 4).
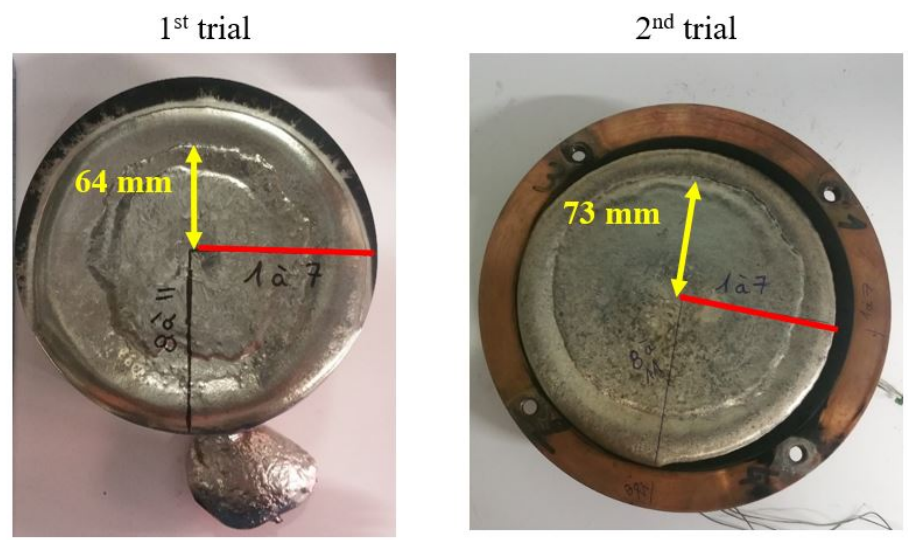
Figure 3. Average bath radius at the end of the melt

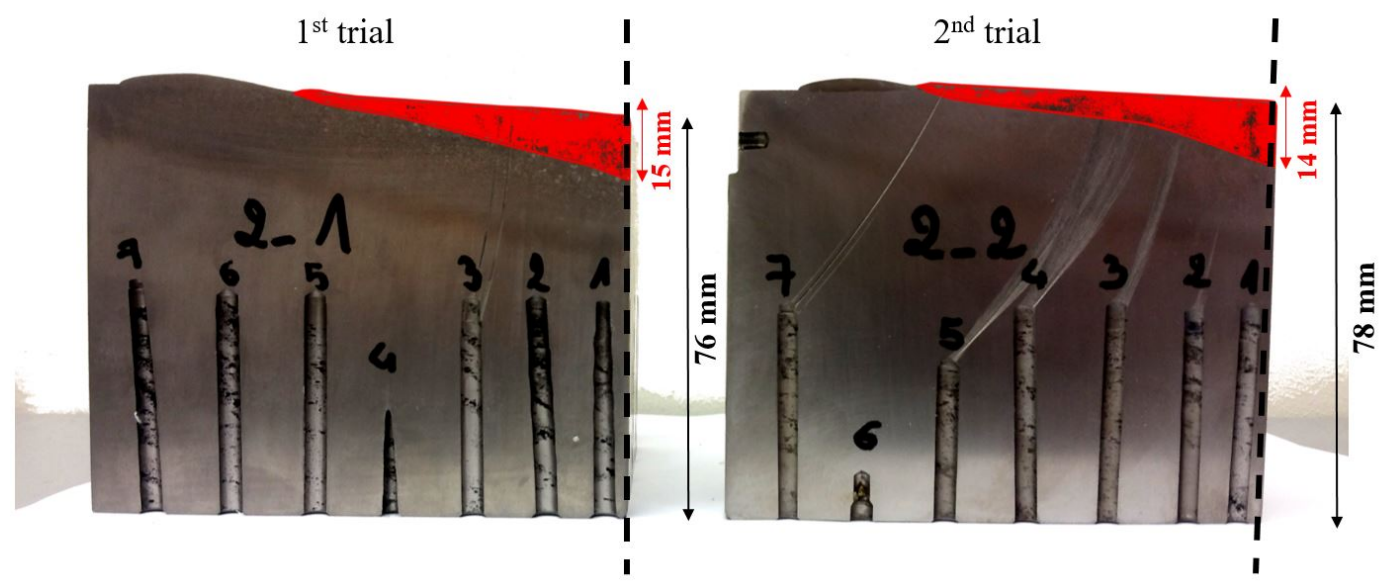

Figure 4. Liquid depth (in red) at the end of the melt

The evolution of the measured temperatures is in the same range of value for thermocouples positioned at the same distance from the torch plasma (see Figure 5). The small differences can be explained by:

- An uncertainty in the alignment of the torch center and the center of the cylinder (for both trials).

- Again, the melting time is longer for the second trial, which increases the temperature.

However, we cannot notice any significant difference which could be attributed to a variation in the bath hydrodynamics caused by a different electrical behavior. 


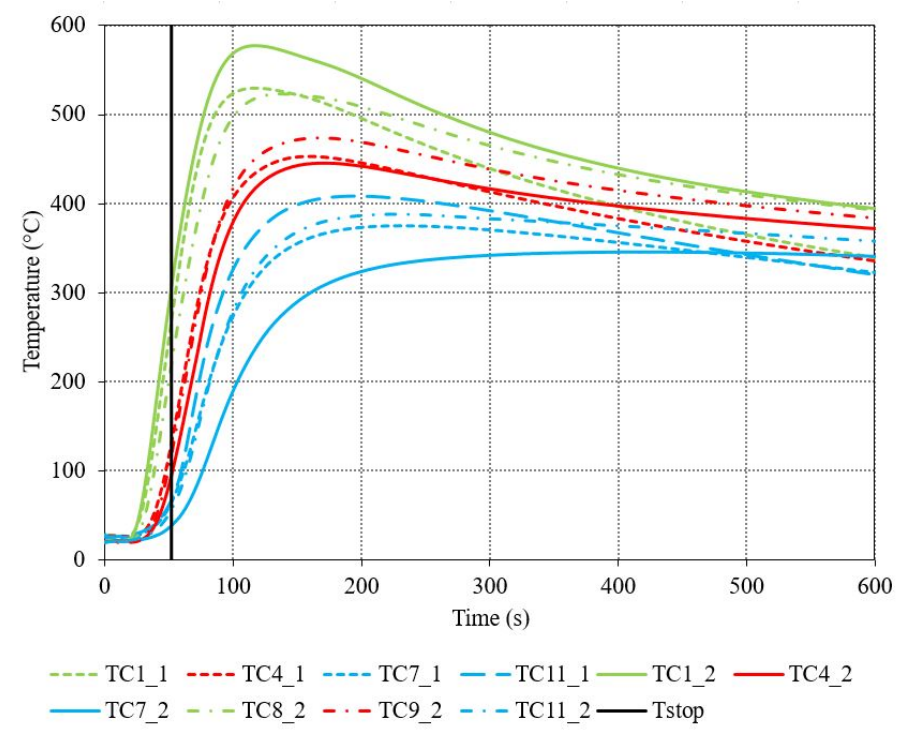

Figure 5. Temperature measured by the thermocouples for both trials

For this reason, an average of the two experimental results will be considered, in order to be compared to the numerical results. Thus, the final metal bath is assumed to exhibit a $15 \mathrm{~mm}$ depth and a $69 \mathrm{~mm}$ radius, for a torch heating time of 52 s. Figure 6 depicts the average temperature at three locations: position 1 (P1) is the average of TC 8 and TC1 for both trials, position $2(\mathrm{P} 2)$ is the average of TC4 and TC9 for both trials, and position $3(\mathrm{P} 3)$ is the average of TC9 and TC11 for both trials. 


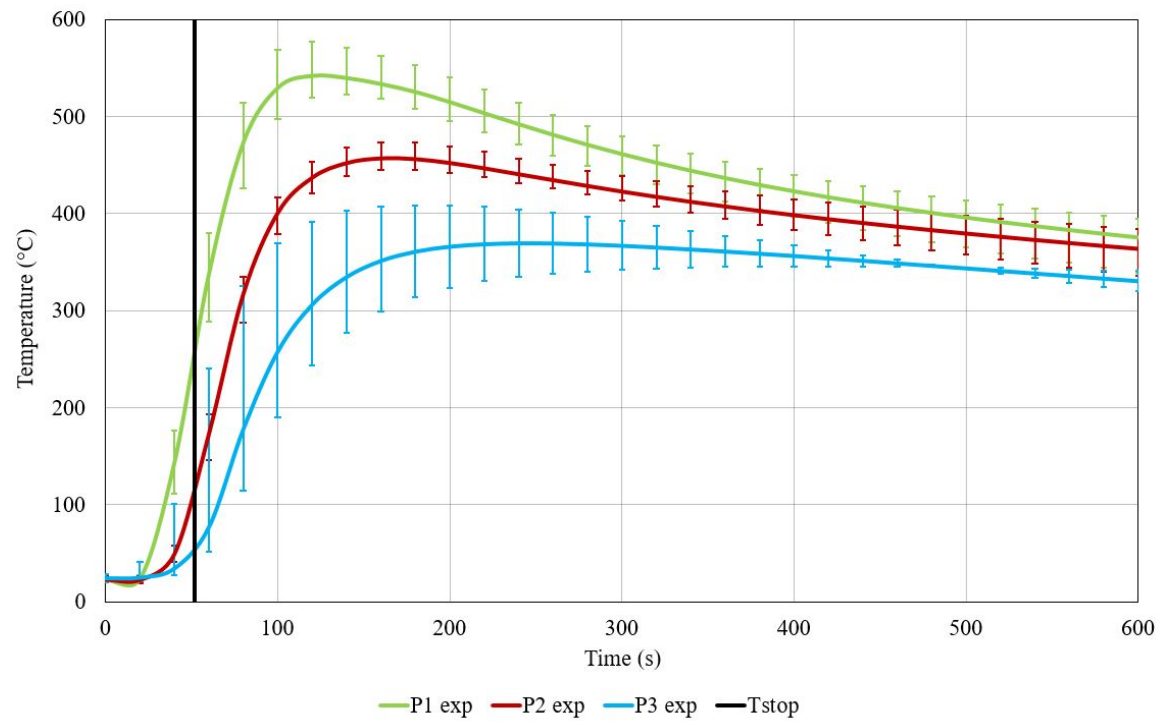

Figure 6. Average temperature and minimum/maximum at three thermocouple positions

\section{Model description}

The $2 \mathrm{D}$ axisymmetric model uses the finite volume method. The heat diffusion equation (eq. 1) is solved to calculate the transient temperature response in the Ti64 cylinder. This equation also takes into account the melting of the material (eq. 2). Moreover, the Laplace equation (eq. 3) is solved by the model to compute the current density (eq. 4), self-induced magnetic field (eq. 5), and resulting Lorenz (or electromagnetic) forces (eq. 6).

$$
\rho C_{p}^{\star} \frac{\partial T}{\partial t}=-\nabla \cdot(-\lambda \nabla T)
$$

Where:

$$
\begin{gathered}
C_{p}^{\star}=C_{p}+\frac{L}{T_{l i q}-T_{\text {sol }}} \text { if } T_{\text {sol }} \leq T \leq T_{\text {liq }} \\
\Delta U=0 \\
\vec{J}=-\sigma_{e l} \nabla U \\
\nabla \times \vec{B}=\mu_{0} \vec{J} \\
\vec{F}_{L}=\vec{J} \otimes \vec{B}
\end{gathered}
$$


Figure 7 presents the meshing strategy: the test block is modeled in $2 \mathrm{D}(\mathrm{r}, \mathrm{z})$ by a rectangular domain in which a regular mesh is typically composed of 2500 cells.

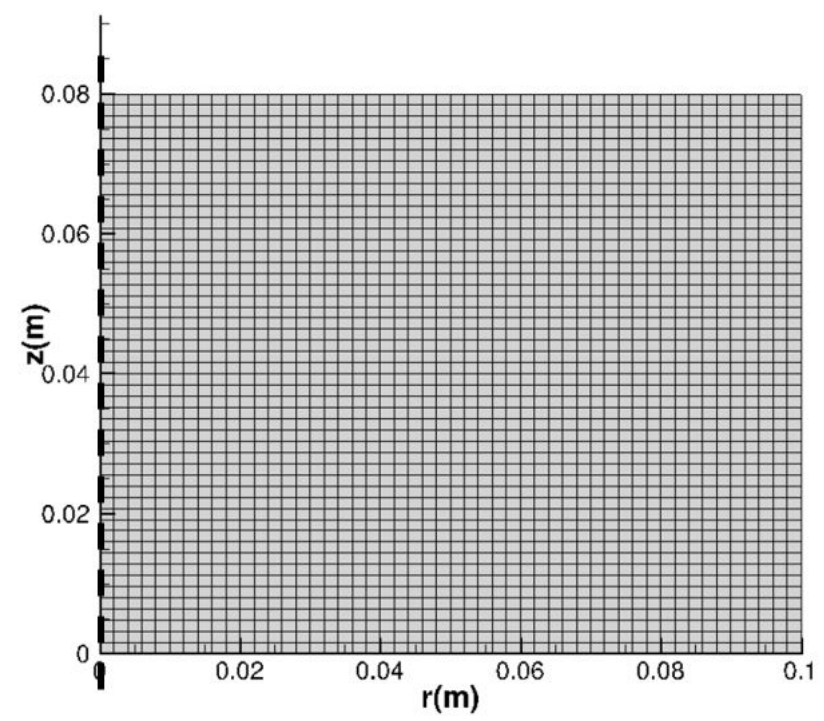

Figure 7. Mesh of the 2D model domain

\section{Thermal boundary conditions}

\section{Top surface}

The heat transfer at the top surface includes heat input from the plasma plume ( $\varphi$ torch (r) in eq. 7) and heat loss by thermal radiation (second term in eq. 7) toward the furnace walls.

$$
\varphi_{\text {surf }}(r)=\varphi_{\text {torch }}(r)-\sigma_{s} \varepsilon\left(T_{\text {surf }}^{4}-T_{\text {wall }}^{4}\right)
$$

Where:

$$
\varphi_{\text {torch }}(r)=\left[\alpha_{\text {conv }} \varphi_{\text {conv }}^{*}(r)+\alpha_{\text {elec }}(r) \varphi_{\text {elec }}^{*}(r)+\alpha_{\text {rad }} \varphi_{\text {rad }}^{*}(r)\right] \eta_{t} U I
$$

The heat flux density $\varphi$ torch (r) is the product of the thermal torch power $\eta_{\mathrm{t}} \mathrm{U}$ I (where $\eta_{\mathrm{t}}$ is the efficiency of the torch) by the sum of three distributions $\varphi$ i(r) weighted by factors $\alpha \mathrm{i}$.

The mathematical expressions of the convective-diffusive and electric contributions (see $\S 2$ ) have been calculated by means of a simplified 2D modelling of the plasma jet flow on a surface. The shape of the convective-diffusive contribution (Figure 8a) was determined using the Reynolds analogy, which expresses the proportionality between the shear stress and 
convective heat transfer at the bath surface. The stagnation point of the shear stress under the plasma jet results in a nearly log-normal distribution for the convective-diffusive term.

Based on the thermodynamic equilibrium in the plasma plume, the electric distribution (Figure $8 \mathrm{~b}$ ) is proportional to the value of the mass flux density of helium, calculated by the 2D model of the plasma jet flow.

Furthermore, if we assume the plasma column geometry to be cylindrical, the shape of the radiative contribution (Figure $8 \mathrm{c}$ ) is deduced from the calculation of shape factors between the surface of the column which thermally radiates on a surface element of the bath.

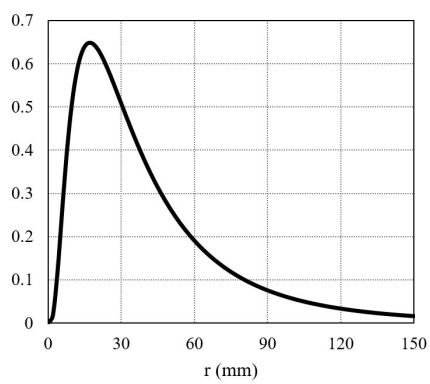

Figure 8a. non-scaled convectodffusive distribution

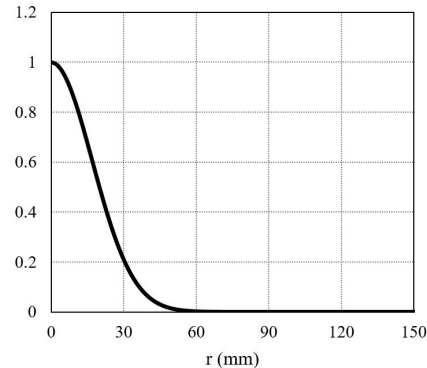

Figure 8b. non-scaled electric distribution

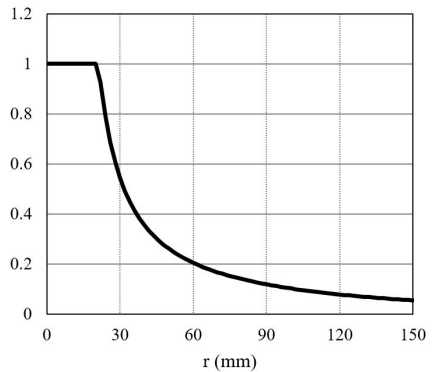

Figure 8c. non-scaled radiative distribution

The values of the weighting factors $\alpha \mathrm{i}$ and of the heat efficiency of the torch $\eta_{\mathrm{t}}$ (see eq. 8) are not known. Only the comparison between the model results and the actual measurements can enable us to determine them.

\section{Lateral and bottom surfaces}

A simple Fourier condition is used to describe the heat transfer at these interfaces. The ambient temperature is Tamb $=20$ ${ }^{\circ} \mathrm{C}$, and the value of the heat transfer coefficient is set to hwall $=10 \mathrm{~W} / \mathrm{m} 2 / \mathrm{K}$.

$$
\varphi_{\text {wall }}=h_{\text {wall }}\left(T_{\text {metal }}-T_{a m b}\right)
$$

\section{Electric boundary conditions}

\section{Top surface}

The top surface condition is the same for both trials. The current density reaches the bath surface through the impact of the plasma column assimilated to a cylinder with a radius rt.

$$
r \leq r_{t} \quad J_{z}=\frac{I}{\pi r_{t}^{2}} \quad ; \quad r>r_{t} \quad J_{z}=0
$$


Lateral and bottom surfaces (trial 2)

Lateral surface:

$$
J_{r}=0
$$

Bottom surface:

$$
U=0
$$

On the lateral wall, a copper crown (see Figure 1a) is placed between $\mathrm{z}=\mathrm{zinf}$ and $\mathrm{z}=\mathrm{zsup}$.

Lateral surface:

$$
z_{\text {inf }} \leq z \leq z_{\text {sup }} \quad U=0 ; z<z_{\text {inf }} \text { and } z>z_{\text {sup }} J_{r}=0
$$

Bottom surface:

$$
J_{z}=0
$$

\section{Results and discussion}

The thermo-physical properties of Ti64 are compiled in Table 1 [8]. The density and specific heat are assumed to remain constant. However, the thermal conductivity is dependent of the temperature in the solid phase [9] and anisotropic in nature in the liquid phase: In the radial direction, it is artificially increased to take roughly into account the heat transfer by radial convection and movement induced by the blowing of the plasma at the surface.

Table 1. Physical properties of Ti-6Al-4V

\begin{tabular}{|c|c|c|}
\hline Liquidus temperature $(\mathrm{K})$ & $\mathrm{T}_{\text {liq }}$ & 1946.5 \\
\hline Solidus temperature $(\mathrm{K})$ & $\mathrm{T}_{\mathrm{sol}}$ & 1926.5 \\
\hline Latent heat of fusion $(\mathrm{kJ} / \mathrm{kg})$ & $\mathrm{L}$ & 400 \\
\hline Thermal conductivity $(\mathrm{W} / \mathrm{m} / \mathrm{K})$ & $\lambda$ & {$[9]$} \\
\hline Density $(\mathrm{kg} / \mathrm{m} 3)$ & $\rho$ & 4110 \\
\hline Specific heat $(\mathrm{J} / \mathrm{kg} / \mathrm{K})$ & $\mathrm{C}_{\mathrm{p}}$ & 794.2 \\
\hline Emissivity of the liquid phase & $\varepsilon_{1 \mathrm{q}}$ & 0.23 \\
\hline Emissivity of the solid phase & $\varepsilon_{\text {sol }}$ & 0.6 \\
\hline
\end{tabular}

\section{Heat transfer}

As stated above, a comparison of the predicted bath profile at the end of melting with the experimental result (Figures 3 and 4) leads to the determination of optimal values for the efficiency $\eta_{\mathrm{t}}$ and the weighting coefficients $\alpha \mathrm{i}$. With these "optimal" values (which cannot be reported here for reasons of confidentiality), the heat flux distribution at the surface of the block is shown on Figure 9: the shape of the curve is similar to the heat flux distribution proposed by Li et al. [2]. Experimental and simulated volumes of the pool match very well. However, some disparities are still apparent (see Figure 
10) between the numerically computed and experimentally recorded temperatures.

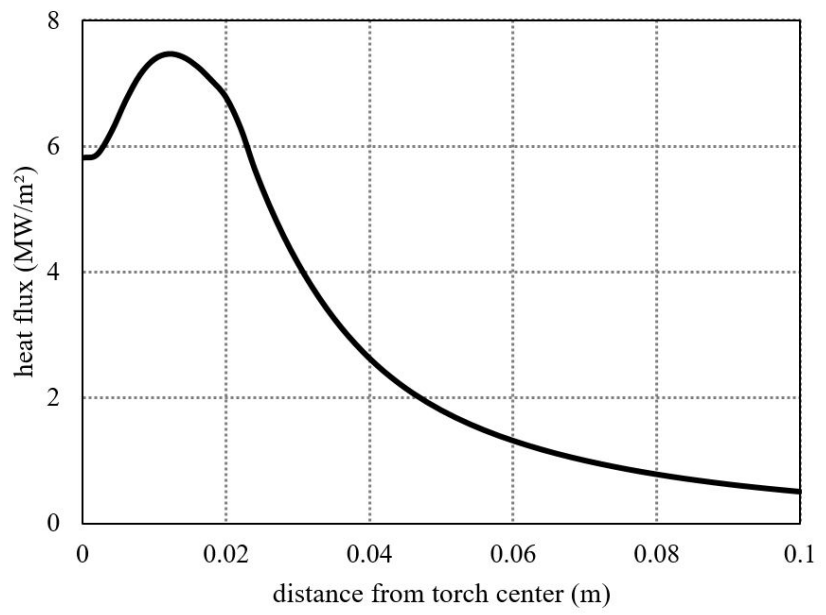

Figure 9. Heat flux distribution at the block surface

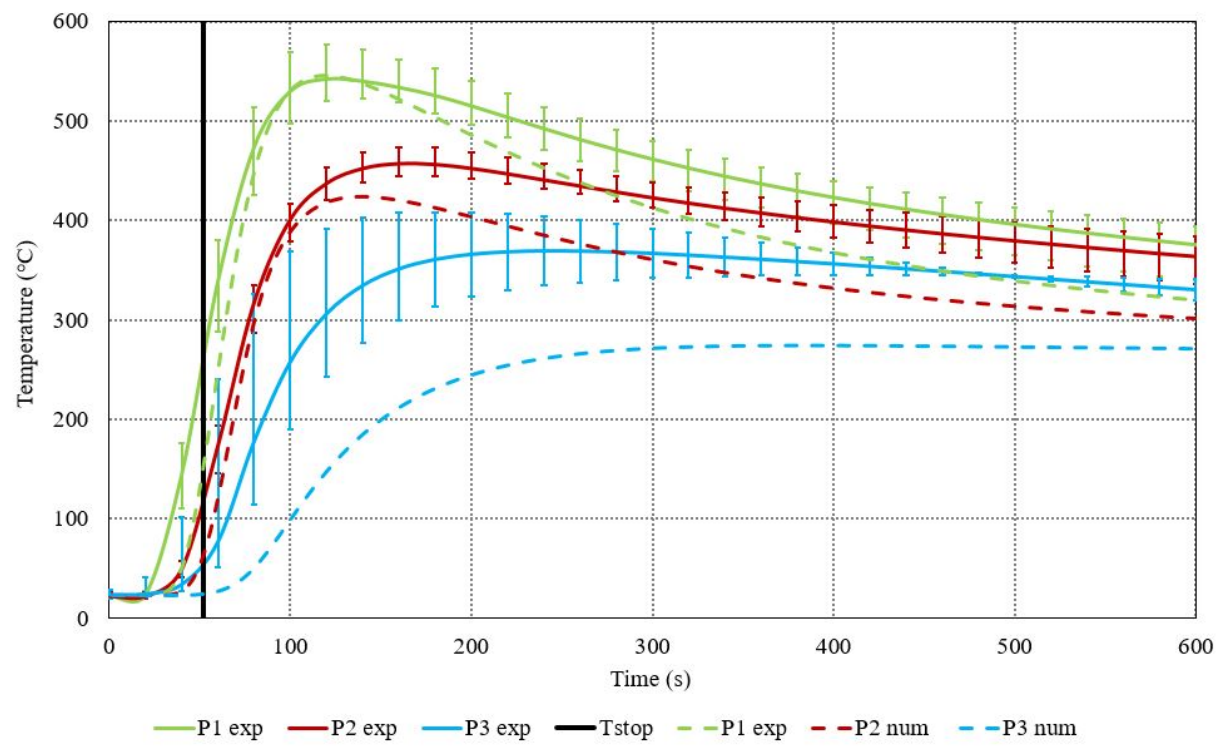

Figure 10. Comparison between numerically computed and experimentally recorded temperatures

The difference increases with the distance of the thermocouples from the impact of the torch. It may arise from a lack of knowledge in the boundary conditions after extinction of the plasma torch. Nevertheless, the "numerical" temperature at P1 and the shape of the bath, which are the least sensitive results to these boundary conditions, are close to experimental 
measurements. These results validate the $\varphi$ torch(r) distribution, hence the values of ${ }_{7 \lambda} \mathrm{i}$ and ${ }_{2 E} t$, which will be implemented in our future model of the PAMCHR process.

\section{Electromagnetic stirring}

The orientation and magnitude of the computed Lorentz forces are depicted for the first and second trial in Figure 11a and Figure 11b, respectively. The black line on these figures represents the liquid bath profile. Lorentz forces were similar in both trials: they are localized under the torch with a maximum value of $19 \mathrm{kN} / \mathrm{m} 3$ and decrease rapidly $(2 \mathrm{kN} / \mathrm{m} 3$ at a distance of $15 \mathrm{~mm}$ ). This similarity is responsible for the similar results observed in the paragraph Results comparison of the two trials.

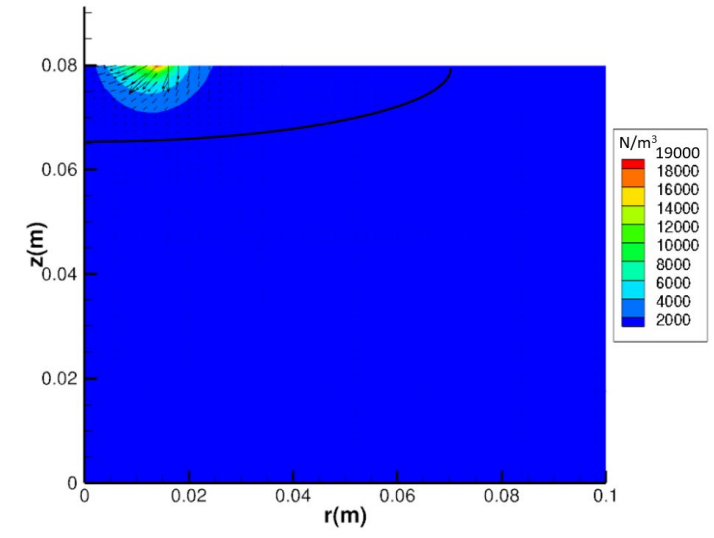

Figure 11a. Orientation and magnitude of the computed Lorentz forces (trial 1)

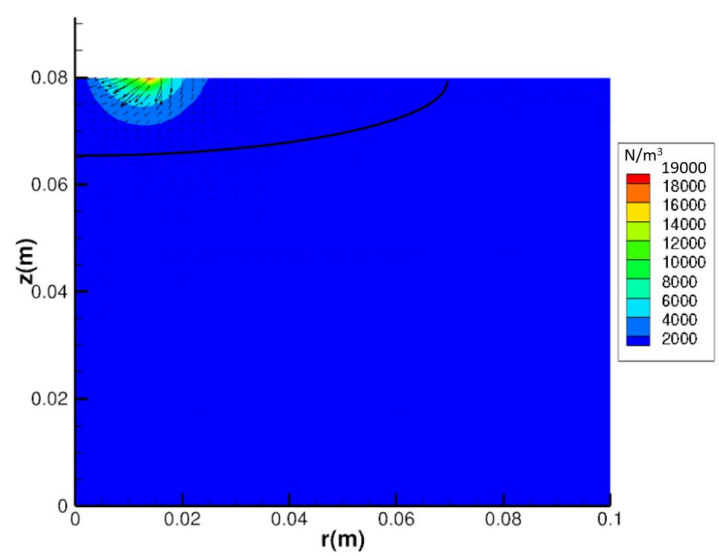

Figure 11b. Orientation and magnitude of the computed Lorentz forces (trial 2)

Unfortunately, it is not possible yet to conclude on the importance of electromagnetic stirring on the liquid bath flow. However this volume force can be compared with the gravitational force (buoyancy) by calculating the curls of these two forces. Indeed, such calculation reflects the recirculating motion created by a volume force. The ratio of these curls is presented on Figure 12. Lorentz forces are much larger than the buoyancy force just below the impact of the torch, therefore they cannot be neglected for a future computation of the overall fluid flow. 


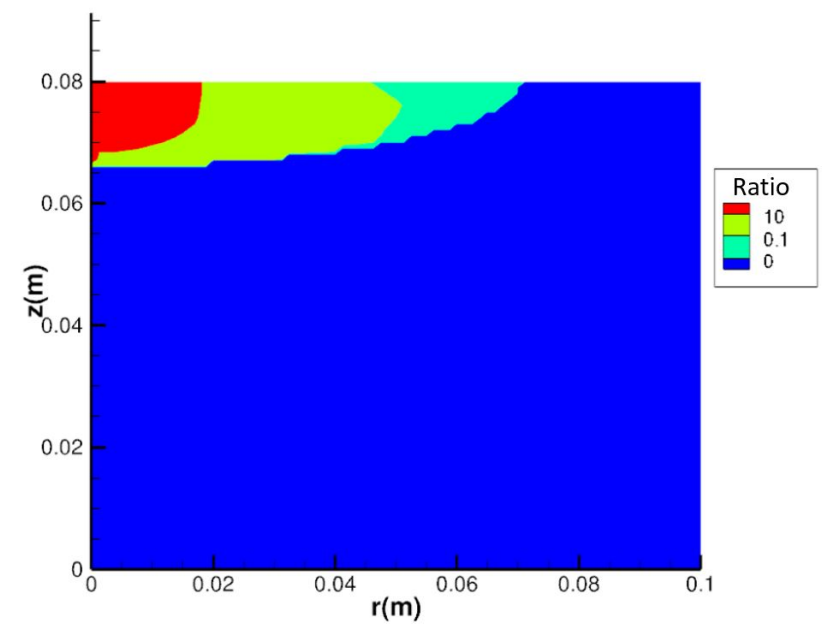

Figure 12. Computed ratio (curl of Lorentz forces / curl of buoyancy force)

\section{Conclusion and perspectives}

Thermal results (temperature measurements and final bath shape) from trials carried out on a PAMCHR pilot furnace have been compared to numerical results of a simple 2D axisymmetric model, in order to determine the distribution of the heat flux transferred from the plasma jet to the metal surface under the conditions of the PAMCHR process. Thus, this heat flux distribution will be implemented in a thermo-hydrodynamic 3D model of the PAMCHR process developed in parallel in Nancy [9].

In addition, the model computes the Lorentz forces, to be compared to buoyancy in the liquid bath. Electromagnetic stirring is localized near the impact of the torch, however it cannot be neglected. A more comprehensive model of the trials should be achieved to take into account several phenomena such as hydrodynamics of the liquid bath, Marangoni shear stress and the blowing of the torch on the surface as well.

\section{Nomenclature}

Latin letters:

$\vec{B} \quad$ magnetic field (T)

$C_{p} \quad$ specific heat $(\mathrm{J} / \mathrm{kg} / \mathrm{K})$

$\vec{F}_{l} \quad$ Lorentz force $\left(\mathrm{N} / \mathrm{m}^{3}\right)$

$h_{\text {wall }}$ heat transfer coefficient at the walls $\left(\mathrm{W} / \mathrm{m}^{2}\right)$
Greek letters:

$\alpha_{i} \quad$ weighed factors of a heat transfer contribution i

$\varepsilon_{\text {liq }} \quad$ emissivity of the liquid phase

$\varepsilon_{\text {sol }} \quad$ emissivity of the solid phase

heat efficiency of the torch 


\begin{tabular}{|c|c|c|c|}
\hline$I$ & intensity of the plasma torch (A) & $\lambda$ & thermal conductivity $(\mathrm{W} / \mathrm{m} / \mathrm{K})$ \\
\hline$\vec{J}$ & current density $\left(\mathrm{A} / \mathrm{m}^{2}\right)$ & $\rho$ & density $\left(\mathrm{kg} / \mathrm{m}^{3}\right)$ \\
\hline$L$ & latent heat of melting $(\mathrm{J} / \mathrm{kg})$ & $\sigma_{e l}$ & electrical conductivity $(\mathrm{S} / \mathrm{m})$ \\
\hline$r$ & distance from the plasma torch center $(\mathrm{m})$ & $\sigma_{S}$ & Stefan-Boltzmann constant $\left(\mathrm{W} / \mathrm{m}^{2} / \mathrm{K}^{4}\right)$ \\
\hline$r_{t}$ & radius of the plasma torch $(\mathrm{m})$ & $\varphi_{\text {surf }}$ & heat flux density at the top surface $\left(\mathrm{W} / \mathrm{m}^{2}\right)$ \\
\hline$T$ & temperature $(\mathrm{K})$ & $\varphi_{\text {torch }}$ & heat flux density from the plasma torch $\left(\mathrm{W} / \mathrm{m}^{2}\right)$ \\
\hline$T_{l i q}$ & liquidus temperature $(\mathrm{K})$ & $\varphi_{\text {wall }}$ & heat flux density on the wall $\left(\mathrm{W} / \mathrm{m}^{2}\right)$ \\
\hline$T_{\text {sol }}$ & solidus temperature $(\mathrm{K})$ & $\varphi_{i}{ }^{*}$ & scaled distribution of a heat transfer contribution $\mathrm{i}$ \\
\hline$U$ & voltage (V) & & \\
\hline
\end{tabular}

\section{References}

1 X. Huang, J.S. Chou, D. Tilly and K-O. Yu, "Computer simulation of the refining hearth in a plasma arc melting process", Proceedings Int. Conf. on Liquid Metal Processing and Casting, (1997) 179-203.

2 G. Li, J.S. Chou, X. Huang, K.M. Kelkar and Y. Pang, "Modeling of a Reversed-Polarity Plasma Torch in Titanium Hearth Melting Process" Proceedings Int. Conf. on Liquid Metal Processing and Casting, (2017) 256-272.

3 L. Trendy, "Modélisation du chauffage de bains métalliques par un plasma d'arc transféré" (Ph.D thesis Ecole Centrale Paris, 1997).

4 A. Douce, "Modélisation 3-D du chauffage d'un bain métallique par plasma d'arc transféré. Application à un réacteur axisymétrique" (Ph.D thesis, Ecole Centrale Paris, 1999).

5 J-P. Trelles, C. Chazelas, A. Vardelle, J-V-R. Heberlein, “Arc Plasma Torch Modeling” Journal of Thermal Spray Technology, (2009) 728-752.

6 S. Ji, J. Duan, L. Yao, D.M. Maijer, S-L. Cockcroft, D. Fiore, and D-W. Tripp, "Quantification of the heat transfer during the plasma arc re-melting of titanium alloys”, Int. J. Heat Mass Transfer, vol. 119, (2018) 271-281.

7 L. Yao, D. Maijer, S. Cockcroft, D. Fiore and D. Tripp, "Quantification of the heat transfer phenomena within the melt pool during the plasma arc re-melting of titanium alloys" Int J. Heat Mass Transfer, vol. 126, (2018) 1123-1133.

8 E. Hess, "Etude du procédé EBCHR : modélisation du comportement des inclusions de type hard-alpha et du métal au sein du four à surverse", (Ph.D thesis, Institut National Polytechnique de Lorraine, 1997).

9 L. Décultot, A. Jardy, S. Hans, E. Doridot, J. Delfosse, F. Ruby-Meyer and J-P. Bellot, "Thermo-hydrodynamic 
modeling of the Plasma Arc Melting Cold Hearth Refining Process (PAMCHR)", Proceedings Int. Conf. on Liquid Metal Processing and Casting, (2019). 